IP Periodica Polytechnica

Transportation Engineering

45(3), pp. 107-118, 2017

https://doi.org/10.3311/PPtr.9270

Creative Commons Attribution (i)

RESEARCH ARTICLE

\section{Functional Modelling of the Air Traffic Control and the Integration Perspectives of the Integrated Services}

\author{
Zsolt Sándor $^{1^{*}}$
}

Received 30 May 2016; accepted 03 December 2016

\begin{abstract}
Aviation is the sector within transportation which manages the most data during operation. Air traffic control has a specific position, because it needs a significant amount of data in order to fulfil its tasks and its complex processes require close cooperation between the organizational units within the whole sector. These data are provided by the industry partners on mandatory base, in their own interest, in good quality. This article explores the structure and organization of air traffic control, the functions fulfilled during the operation of the organization and the managed data connected to these functions as well as the strategic possibilities of forming integrated solutions. Necessary information for the tasks can be identified by the functional modelling of air traffic control. The elaborated model provides the basis for the establishment of complex content provider systems which can manage information regarding air traffic control and even aviation related data jointly. The application of these systems contributes to the increase of the efficiency of traffic operations and the more economical operations even in case of air or ground based aviation organizations.
\end{abstract}

\section{Keywords}

air traffic management, air traffic control, aviation information system, functional modelling, analysis of information systems, information structure

\footnotetext{
${ }^{1}$ ATS Operations and Airport Coordination Department, HungaroControl Hungarian Air Navigation Services H-1185 Budapest, 33-35. Igló Street, Hungary

*Corresponding author, e-mail: zsolt.sandor@hungarocontrol.hu
}

\section{Introduction}

Within transportation, aviation is the most standardized and most regulated sector due to its international nature. These processes started after the Second World War when the boom of the industry had begun. Nevertheless, it is the most under-documented sector from a scientific viewpoint. The international scientific literature contains few scientific publications which present research findings and methods conducted by a systemoriented approach in the field of comprehensive functional modelling of air traffic control.

In connection with the shuttle of the aircrafts a significant amount of data is generated concerning the industry partners (airlines, airports, air navigation service centres, etc.) - more than in any other sector of transportation. However, the complex processing and usage of these data is not fulfilled, the data analysis is realized typically only on micro-level, although the need for the fulfilment of macro-level analyses also appears. Macro level analysis means the global summary of the available data, while micro level analysis refers to a more precise, detailed and comprehensive examination of the available data.

Out of the collected data the actors process and storage only the ones that are necessary and useful date for their work. Partially it is because of the market competition and the fear of competitors, partially because of the significant fragmentation of the connected systems.

This happens despite the fact that nowadays the computing and storage capacity can manage the data quantities which are generated in connection with aviation. Currently, air navigation service providers (ANSP) and airlines are those entities where aviation related data are mostly concentrated. While airlines manage data connected to their flights and fleet (typically air side data), air navigation service providers collect and manage data on a border spectrum in their area of competence. For more efficient traffic management, ANSPs have already formed the channels with which information can be shared, thus increasing the efficiency of traffic control on every time scale of flying (strategic, tactical and operational level of planning). 
The sharing of different information is realized by the use of diverse, totally independent systems in most cases. Thus the information sharing between the adjacent or directly (functionally) connected services is achieved whereas the integrated data management with other systems and services is not (ICAO Doc 10039). Information sharing can be done by event and / or time controlled direct data handling between two services or with data queries from a central system to which the access is granted in advance.

The purpose of the SWIM (System Wide Information Management) initiation - supported by the FAA and EUROCONTROL - is to perform a common platform for the industry partners where all the necessary information is available comprehensively in this way supporting them in the development of more efficient air transport. In the interest of this, the industry has set the objective of the integrated management of the data comming from different systems (Kampichler and Eier, 2014; SWIM Concept of Operations, 2013).

The aim of the article is to present the model of the system of information of air traffic control, which contains the managed information systematically and comprehensively with the detail analysis of the air navigation service provider and air traffic control fulfilled by the service provider. The model is based on the results of the functional modelling of the services fulfilled by the ANSP. The elaborated analysis connected to the model presents the explored relationships between the identified data elements, thus the results can be considered as a detailed system specification of a complex data model in the field of air transportation management.

The system of information model may provide a basis for the development of complex systems which are able to manage the data related to air traffic control and the data connected to air transport jointly. The interoperable application of complex systems contributes to the increase of the effectiveness of traffic management, safer air transportation, the reduction of environmental effects and the more economical operation of both ground and air operational services.

The comprehensive telematics integration consists of several steps and requires significant time expenditure. The results summarized in the article support these processes by the systematization of the available information, thus facilitating the realization of the SWIM project.

\section{Short literature review}

Relatively few scientific publications have been published in the field of the functional modelling of air traffic management systems. Therefor the completion of modelling work was significantly inhibited and in addition, the use of the earlier works was not feasible.

System developers conduct this kind of research activity in order to analyse customer demands and the possible field of interest, but they are not published due to the intense competitive environment. Documents made by system thinking approach serve primarily demonstration and education purposes, non-academic goals (Bayen and Tomlin, 2005; Boeing NEXTOR Report, 1997; Haraldsdottir et al., 1998; Bayen 2003).

These published documents are not regarded as complex and comprehensive materials because the complex modelling of the air traffic management system is missing from it. Only specific areas of the ATM system have been elaborated ((Zellweger and Donohue, 2001; AE Reports 1988; Nolan 2010). Nonetheless, they have awareness-raising effects, because the human, technical and information managing components of the functional ATM systems have been described jointly.

A significant finding of the literature overview in the field of modelling is that the authors define the "functions" and "functionality" very differently. Authors and scientists typically refer to them as a specific and usually stand-alone activity, yet the expression "function" covers a greater and a significant information managing unit.

Most researchers fully simplify the system thinking approach to a specific action conducted by the air traffic controller. It is generally used for human factor analysis with the application of a psychological approach. Thus researchers examine only a single human action in connection with the controlling during the modelling, in order to alternate the human components with machine systems (Woltjer and Hollnagel, 2008; Ahmad and Saxena, 2008; Cognitive Aspects of Air Traffic Control, 1997; Loft et al., 2007; Prandini et al., 2011).

The different interpretation of the terminology and the relationships results in the fact that researchers mean traffic modelling under the expression "modelling". Within traffic modelling, researchers mean traffic flow modelling and its different aspects.

The use of the expression "function" and "structure" is mixed in literature. Current research is closer to the expression of "structure" but in international literature the word "structure" and its combination is used for the physical structure of the airspace and the computer network (Menon et al., 2004; Filho and Falcão 2012).

Despite the fact that a number of modelling methods are described in literature, its use for the comprehensive modelling of the functional AMT system with system thinking approach has not been conducted yet. The structured analysis and design technique (SADT) (Marca and McGowan, 1988; Ross, 1977; 1985), later standardized into the modelling language IDEF0, is an elaborate and well-defined functional modelling language.

The functional resonance accident model (FRAM) describes socio-technical systems by the functions they perform rather than by their structure, and aims to capture the dynamics of such systems by modelling non-linear dependencies and variability with which functions are performed (Hollnagel, 2004).

These kinds of modelling methods are used only for the description of specific tasks, while they have significant potential. 


\section{The model of the information system of air traffic control}

During the modelling, both the information system ${ }^{1}$ and the system of information ${ }^{2}$ were analysed from a structural and operational viewpoint in order to identify the components (services), processes inside them (information managing procedures) and the connected information (managed data) as well as the machine systems required for the performance of these.

During the development of the model I took the static (construction) and dynamic (operation) structures of the ANSP and the functional air traffic management (ATM) system into consideration, moreover the system of air traffic control were also analysed.

The machine systems and the process inside them were not analysed in detail because their solutions significantly depend on the actual level of technical development. Nevertheless, the functions of the machine systems were identified in each case. Thus, the conclusions are limited to the system of information of the air traffic management in order to achieve a result valid for a long period. The modelling of the system of information also assumes the (structural and operational) modelling of the functional ATM system, because the data map the components and processes.

As a system air transportation consists of the members involved in the aviation processes and the multitude of the information systems of the industry members together. The latter one influences the operation. The system of information of the air traffic management, which is the basis of current article, is located within the information system. The information systems provide the management of the basic processes and, built upon it, serving the industry members.

Figure 1 illustrates the elaborated information model of air traffic management and its environment. The system components are indicated in the figure (services, functions, datasets). Regarding the service-function approach the main arranging principle is the function. The characteristics of organizations may often change, while the functions are mostly permanent (in the field of air traffic management pre-defined functions must be provided).

Machine (sub)systems - which contain several functional subsystems - interconnect the components of the information system and they provide the storage, transmission and

1 Information system: is part of the company (subsystem), which provides procedures for creating, recording, processing and accessing the information. It is related either to the organization or to its specific part and it assists the organization to reach its goal. Information systems are the representations of the organizations, which provide information about the status of the organization for the managing elements located at different levels in the hierarchy. For this purpose the machine system of the organization is used, which may consist of several subsystems.

2 System of information: is a structured system of data, a set of wellstructured and well-systematized information considering certain aspects. Part of the information system. procession of the information necessary for the operation. In addition, they are interfaces between the users, the information system and the (main and sub)systems of the industrial members in order to perform the data transmission.

In the field of air traffic management, due to the high level of standardization and controlling, the information managing procedures are well and precisely defined. Thus, the information managing procedures can be unequivocally assigned to the information managing elements (human components) - in most cases. Accordingly, as far as functionality is concerned, connections between the services and functions can be formed without overlapping.

The machine systems may overlap functionally due to complexity. From the point of view of functions, the assignment between the information managing elements and procedures, as far as the subsystems are concerned, can be defined unequivocally and without overlapping.

Based on the relationships of the components I elaborated the system of information of air traffic management. In order to this, I revealed and analysed the information managed by the air traffic management agencies. Incorporating the managed information into a uniform system, I developed the model of the system of information of air traffic management.

\section{Modelling method of the information structure}

During the elaboration of the model within the ANSP, the structure, components and the procedures of the air traffic management system were mapped and the machine (sub)systems were also identified. An approach with sequence of service, function, dataset has been applied - supplemented with the applied machine (sub)systems. The investigation was gradually broadened both horizontally (model wideness) and vertically (model breakdowns). The broadening directions are discretely separated from each other. Figure 2 summarizes the modelling steps and its logic. The sequence of the steps follow a logical superposition according to the system and process-oriented approach.

\subsection{Step 1: Identification of components}

Main components:

- Service (notation: $S_{n}$ ),

- Function (notation: $F_{n}$ ),

- Dataset (notation: ),

- Machine (sub)system (notation: $M_{n}$ )*

* The analysis of the machine (sub)system does not form the basis of this article. It is indicated only for better understanding. 


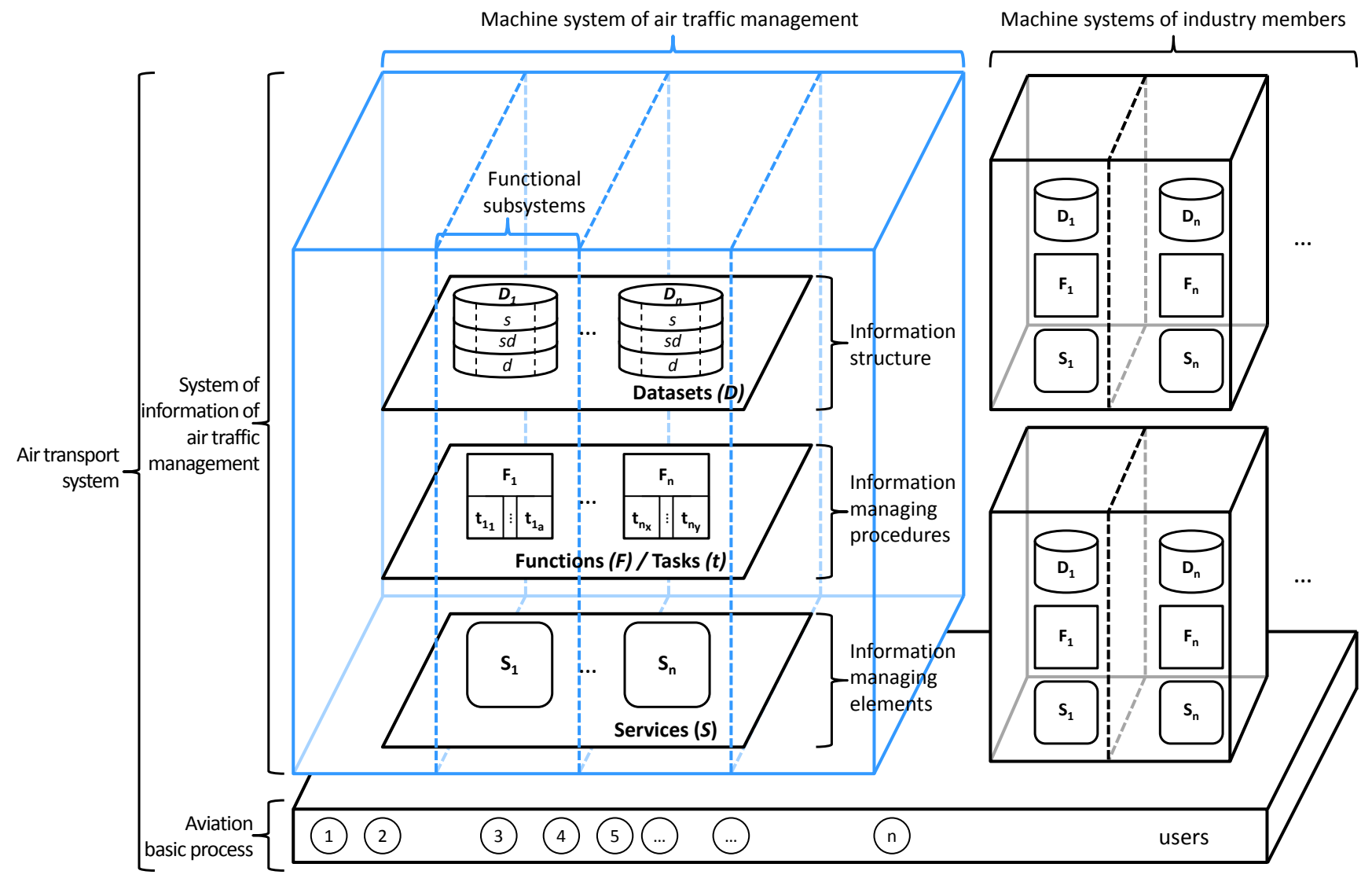

Fig. 1 Model of the system of information of air traffic management

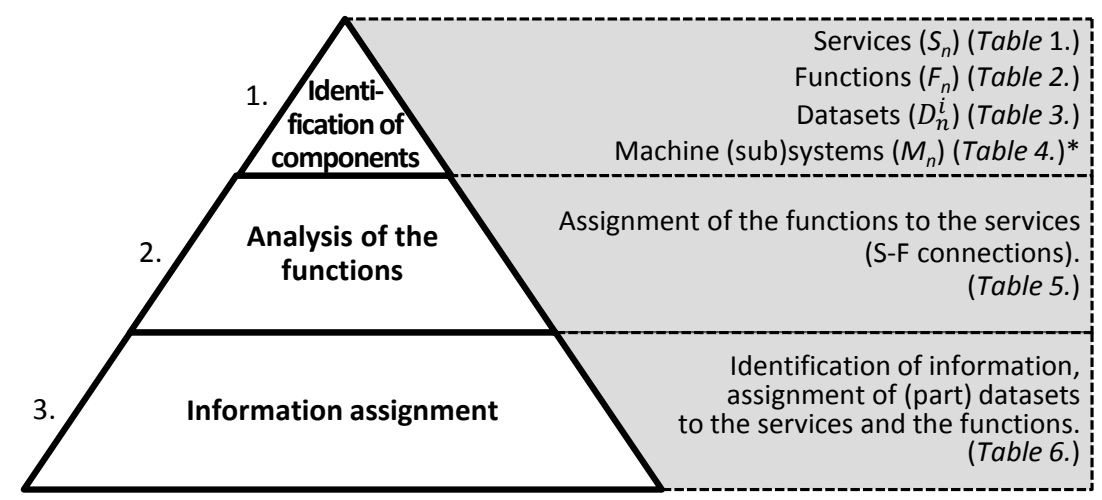

Fig. 2 Steps of the modelling of the information structure

\section{Services $\left(S_{n}\right)$}

Within the air navigation service provider the members of the functional ATM system were grouped based on their scope of duties (main tasks related to the base process of aviation) (Table 1). Regarding the complexity of the functional ATM system, the table contains the higher level classification of the given services into functional blocks. Descriptions of the services are indicated in the brackets after their name.

\section{Functions $\left(F_{n}\right)$}

Based on the duties and the connecting services related to the provision of air traffic control, the main functions have been determined and these functions have been classified into higher level functional blocks $\left(\boldsymbol{F} \boldsymbol{B}_{n}\right)$. The results are indicated in Table 2. The not well-known features are explained after the table.

\section{Datasets $\left(D_{n}^{i}\right)$}

The managed data were sorted into groups by the content and the temporal validity in order the conformability and the orderliness. Table 3 illustrates the results with examples. In this way, the data which are similar but map different content can be managed together. During the analysis those data were identified which are directly connected to the operative air traffic control activities. The following datasets were identified:

1. Traffic and route data (flights, aircrafts and movements data)

2. Airspace and sector data (data related to airspace structure and air infrastructure)

3. Information data (data necessary for the safe operation of flights)

4. Equipment data (data related to technical infrastructure) 
Static data are unchanged for a longer period, their temporal invariance is greater than one month. Semi-dynamic data may contain a more frequently changing content, thus their temporal invariance may change between one month and a few hours. The temporal invariance of the dynamic data has a much smaller invariance, it may change even every second.

Notation of the data: $n$ indicates the number of the dataset, $i$ indicates the dynamism.

\section{Dynamism:}

- S - static,

- SD - semi-dynamic,

- D - dynamic (included the real time data too).

\section{Machine systems $\left(M_{n}\right)$}

The machine systems - and functional subsystems within them - support the fulfilment of activities related to air traffic control. In most cases, each system operates independently without any integration. Table 4 summarizes the main functional systems used directly or indirectly for air traffic control. The indicated systems are presented in order to illustrate the operation of the whole and complex services. Therefor deviations can be discovered at different ANPSs (some systems can be integrated and contracted based on the real installation and site-specific considerations).

Table 1 Services

\begin{tabular}{|c|c|c|c|c|c|}
\hline Notation & Decomposition of the ANSP for different s & vices and thei & ssification into higher level of $f$ & Inctional block & \\
\hline$S_{1}$ & $\begin{array}{c}\text { Area Control Centre (ACC) } \\
\text { (service which is responsible for the controlling of en-route } \\
\text { aircrafts in a particular volume of controlled airspace ) }\end{array}$ & \multirow{3}{*}{$\begin{array}{l}\text { Air Traffic } \\
\text { Control } \\
\text { services } \\
\text { (ATC) }\end{array}$} & & \multirow{7}{*}{$\begin{array}{l}\text { Air Traffic Management } \\
\text { (ATM) }\end{array}$} & \multirow{17}{*}{$\begin{array}{c}\text { Air } \\
\text { Navigation } \\
\text { Service } \\
\text { Provider } \\
\text { (ANSP) }\end{array}$} \\
\hline $\mathrm{S}_{2}$ & $\begin{array}{c}\text { Approach Control Centre (APP) } \\
\text { (service which is responsible for the controlling of the } \\
\text { departing and arriving aircrafts from / to an airport in the } \\
\text { terminal manoeuvring area) }\end{array}$ & & & & \\
\hline $\mathrm{S}_{3}$ & $\begin{array}{c}\text { Tower Control (TWR) } \\
\text { (service which is responsible for the airport movements, } \\
\text { departures and arrivals of flights and the safe landings and } \\
\text { take-offs) }\end{array}$ & & $\begin{array}{l}\text { Air Traffic } \\
\text { Services } \\
\text { (ATS) }\end{array}$ & & \\
\hline $\mathrm{S}_{4}$ & $\begin{array}{l}\text { Air Traffic Advisory Service (ADV) } \\
\text { (service witch informs the aircraft pilots about the traffic } \\
\text { situation in the uncontrolled airspace) }\end{array}$ & \multirow{2}{*}{$\begin{array}{l}\text { Flight } \\
\text { Information } \\
\text { Centre } \\
\text { (FIC) }\end{array}$} & & & \\
\hline $\mathrm{S}_{5}$ & $\begin{array}{l}\text { Flight Information Service (FIS) } \\
\text { (service which controlls the mandatory information } \\
\text { communication in the uncontrolled airspace) }\end{array}$ & & & & \\
\hline$S_{6}$ & \multicolumn{3}{|c|}{$\begin{array}{c}\text { Airspace Management Cell (AMC) } \\
\text { (service which coordinates the civil and military airspace needs) }\end{array}$} & & \\
\hline $\mathrm{S}_{7}$ & $\begin{array}{r}\text { Flow Management (Unit) (I } \\
\text { (service which performs flight control depending on the } \\
\text { controllers in order to avoid overloaded air tr }\end{array}$ & $\begin{array}{l}\text { IP) } \\
\text { vailable airspac } \\
\text { fic controller w }\end{array}$ & d air traffic & & \\
\hline $\mathrm{S}_{8}$ & \multicolumn{4}{|c|}{$\begin{array}{l}\text { (Aeronautical) Meteorology service (MET) } \\
\text { (service which is responsible for the provision of meteorological data ) }\end{array}$} & \\
\hline $\mathrm{S}_{9}$ & \multicolumn{3}{|c|}{$\begin{array}{c}\text { AFTN network service } \\
\text { (service which ensures the handling of messages transmitted by the AFTN network) }\end{array}$} & \multirow{3}{*}{$\begin{array}{c}\text { CNS-ATM } \\
\text { technical } \\
\text { services }\end{array}$} & \\
\hline$S_{10}$ & \multicolumn{3}{|c|}{$\begin{array}{l}\text { Infrastructure operator technical service for the ATM (CNS) } \\
\text { (service which ensures the operation of the communication, navigation and surveillance systems necessary for air } \\
\text { traffic control - out of ops room) }\end{array}$} & & \\
\hline$S_{11}$ & \multicolumn{3}{|c|}{$\begin{array}{c}\text { System operation service } \\
\text { (service witch ensure the operation of the systems and equipment necessary for the air traffic cc } \\
\text { ops room side) }\end{array}$} & & \\
\hline$S_{12}$ & \multicolumn{3}{|c|}{$\begin{array}{l}\text { NOTAM office } \\
\text { (service which is responsible for the creation and transmission of NOTAM telegrams) }\end{array}$} & \multirow{3}{*}{$\begin{array}{l}\text { Aeronautical } \\
\text { Information } \\
\text { Services } \\
\text { (AIS) }\end{array}$} & \\
\hline$S_{13}$ & \multicolumn{3}{|c|}{$\begin{array}{c}\text { Aerodrome Reporting Office (ARO) } \\
\text { (service which is responsible for the administration of international departing flights) }\end{array}$} & & \\
\hline$S_{14}$ & \multicolumn{3}{|c|}{$\begin{array}{l}\text { Publication and static data management service (PUB/SDM) } \\
\text { (service which manages the aviation related static data and creates the connecting publications) }\end{array}$} & & \\
\hline$S_{15}$ & \multicolumn{3}{|c|}{$\begin{array}{c}\text { Flight safety service (Safety) } \\
\text { (service which manages the aviation safety issues) }\end{array}$} & \multirow{3}{*}{$\begin{array}{l}\text { other, ATM } \\
\text { supporting } \\
\text { services }\end{array}$} & \\
\hline$S_{16}$ & \multicolumn{3}{|c|}{$\begin{array}{c}\text { System development service } \\
\text { (service which takes part in the design and development of the air traffic management and control systems) }\end{array}$} & & \\
\hline$S_{17}$ & \multicolumn{3}{|c|}{$\begin{array}{c}\text { Administration service } \\
\text { (collective term for the supporting areas: law, HR, education, training, etc.) }\end{array}$} & & \\
\hline
\end{tabular}


Table 2 Functions

\begin{tabular}{|c|c|c|c|}
\hline Notation & \multicolumn{2}{|c|}{ Function } & Function block \\
\hline $\mathbf{F}_{1}$ & \multicolumn{2}{|c|}{ Control of en-route fights } & \multirow{5}{*}{$\begin{array}{c}\text { Operative air traffic control of the } \\
\text { controlled airspace - insurance of safe } \\
\text { ansportation of aircrafts within the controlled } \\
\text { airspace }\end{array}$} \\
\hline $\mathbf{F}_{2}$ & \multicolumn{2}{|c|}{ Control of departing, arriving flights within the terminal manoeuvring area (TMA) } & \\
\hline $\mathbf{F}_{3}$ & \multicolumn{2}{|c|}{ Control of aerodrome departing and arriving flights } & \\
\hline $\mathbf{F}_{4}$ & \multicolumn{2}{|c|}{ Flight data management - Data processing and transmission } & \\
\hline $\mathbf{F}_{5}$ & \multicolumn{2}{|c|}{ Insuring the alerting service } & \\
\hline $\mathbf{F}_{6}$ & \multicolumn{2}{|c|}{ Air traffic advisory service } & \multirow{4}{*}{ Managing of uncontrolled airspace } \\
\hline $\mathbf{F}_{7}$ & \multicolumn{2}{|c|}{ Flight information service } & \\
\hline $\mathbf{F}_{8}$ & \multicolumn{2}{|c|}{ Aviation data management - Data processing and transmission } & \\
\hline $\mathbf{F}_{9}$ & \multicolumn{2}{|c|}{ Insuring the alerting service } & \\
\hline $\mathbf{F}_{10}$ & \multicolumn{2}{|c|}{ Pre-tactical airspace management } & \multirow{3}{*}{ Airspace management } \\
\hline$F_{11}$ & \multicolumn{2}{|c|}{ Tactical airspace management } & \\
\hline$F_{12}$ & \multicolumn{2}{|c|}{ Administration } & \\
\hline $\mathbf{F}_{13}$ & \multicolumn{2}{|c|}{ Pre-tactical coordination } & \multirow{4}{*}{ Air traffic flow management } \\
\hline $\mathrm{F}_{14}$ & \multicolumn{2}{|c|}{ Tactical coordination } & \\
\hline $\mathbf{F}_{15}$ & \multicolumn{2}{|c|}{ Cooperation } & \\
\hline$F_{16}$ & \multicolumn{2}{|c|}{ Administration } & \\
\hline $\mathbf{F}_{17}$ & \multicolumn{2}{|c|}{ Aviation meteorology observation and forecasting } & \multirow{3}{*}{ Aviation meteorology services } \\
\hline $\mathrm{F}_{18}$ & Management of aviation meteorology infor & mation necessary for flight services & \\
\hline $\mathbf{F}_{19}$ & $\begin{array}{l}\text { Management of aviation } \mathrm{m} \\
\text { (METAR, TAF, SIGME }\end{array}$ & $\begin{array}{l}\text { eteorology bulletins } \\
\text {, VOLMET, etc.) }\end{array}$ & \\
\hline $\mathbf{F}_{20}$ & \multicolumn{3}{|c|}{ Ensuring the AFTN network services (service supervision, management of messages) } \\
\hline $\mathbf{F}_{21}$ & $\begin{array}{l}\text { Operation of communication and data } \\
\text { transmission devices }\end{array}$ & \multirow{3}{*}{$\begin{array}{l}\text { Operation of the extra-ops room } \\
\text { installed technical infrastructure necessary } \\
\text { for air traffic control }\end{array}$} & \multirow{6}{*}{ Operation of technical infrastructure } \\
\hline $\mathbf{F}_{22}$ & Operation of navigation devices & & \\
\hline $\mathbf{F}_{23}$ & Operation of surveillance and radar systems & & \\
\hline $\mathbf{F}_{24}$ & $\begin{array}{l}\text { Technical supervision and operation of the sys- } \\
\text { tems of the air traffic control centre }\end{array}$ & \multirow{3}{*}{$\begin{array}{l}\text { Operation of the inter-ops room and airport } \\
\text { related technical infrastructure. }\end{array}$} & \\
\hline $\mathbf{F}_{25}$ & $\begin{array}{l}\text { Operation of outdoor (aerodrome) installed techni- } \\
\text { cal equipment }\end{array}$ & & \\
\hline $\mathbf{F}_{26}$ & $\begin{array}{c}\text { Operation of aeronautical telecommunication } \\
\text { networks }\end{array}$ & & \\
\hline $\mathbf{F}_{27}$ & \multicolumn{2}{|c|}{ Management of NOTAM (edition, publishing) } & \multirow{6}{*}{ Aeronautical information service } \\
\hline $\mathbf{F}_{28}$ & Processing flight plans & & \\
\hline $\mathbf{F}_{29}$ & Pre-flight information & Flight reporting & \\
\hline $\mathbf{F}_{30}$ & Post-fight incident reporting & & \\
\hline $\mathbf{F}_{31}$ & Static data man & agement & \\
\hline $\mathbf{F}_{32}$ & AIP editi & & \\
\hline $\mathbf{F}_{33}$ & Incident inves & igation & \\
\hline $\mathbf{F}_{34}$ & Performance of aviation safety $\mathrm{ch}$ & ecks, research and analysis & Supporting the operation of ATM \\
\hline $\mathbf{F}_{35}$ & Development of the ATM system & (hardware and software) & \\
\hline $\mathbf{F}_{36}$ & Administration and other supporting activ & ties necessary for air traffic control & \\
\hline
\end{tabular}

Description of the functions:

$F_{1}$ : Control of aircrafts, flying through the responsible sector; ensuring the horizontal and vertical separation between them necessary for safe flying.

$\mathrm{F}_{2}$ : Control of departing aircrafts in the terminal movement area from the airborne until they reach the predefined transfer level handed over to the ACC. Control of arriving aircrafts while they approach the aerodrome. Ensuring the necessary horizontal and vertical separation between the aircrafts for safe flying.
$\mathrm{F}_{3}$ : $\quad$ Issuing take-off and landing permissions, preparation of departing flights, requesting and giving the necessary permissions and clearances, coordinating the aerodrome movements, receiving the arriving flights, coordinating the surface movements between the runway and the stand assigned to the aircraft.

$\mathrm{F}_{4}, \mathrm{~F}_{8}$ : Management of flight data which require manual intervention and their transmission through international networks and communication plus data transmission with the ATS unit of the adjacent nations.

$\mathrm{F}_{5} \mathrm{~F}_{9}$ : Notification of the competent organizations in case of an aircraft needs search and rescue services in the controlled and uncontrolled airspace. 
$\mathrm{F}_{6}-\mathrm{F}_{7}$ : Information provision for the aircrafts pilots about the actual traffic and meteorology situations and airspace-structure in the uncontrolled airspace.

$\mathrm{F}_{10}$ : Management, coordination of the civil and military airspace usage needs, creation of airspace usage plans.

$\mathrm{F}_{11}$ : Management of actual airspace usage requisitions, coordination about the usage with the airspace claimer.

$\mathrm{F}_{12}$ : All administration action in connection with airspace usage.

$\mathrm{F}_{13}$ : Determination of the expected traffic data and the tactical measures, exchange of environmental data (new capacity data in case of capacity reduction), coordination with the relevant international organizations, load calculation.

$\mathrm{F}_{14}$ : Traffic monitoring, reporting and managing of events influencing the capacity, slot coordination.
$\mathrm{F}_{15}$ : Communication with industry members who are affected by capacity reduction.

$\mathrm{F}_{16}$ : All administration action in connection with air traffic flow management.

$\mathrm{F}_{20}$ : Insuring the continuous services of the national and international AFTN network, continuous monitoring of the telegram forwarding function ensured by the system.

$\mathrm{F}_{31}$ : Management of static data related to flights.

$\mathrm{F}_{32}$ : Editing Aeronautical Information Publications.

$\mathrm{F}_{33}$ : Investigating events and incidents connected to air traffic control.

$F_{36}$ : All activities which ensure the operation of the service and are essential to its operation.

Table 3 Datasets

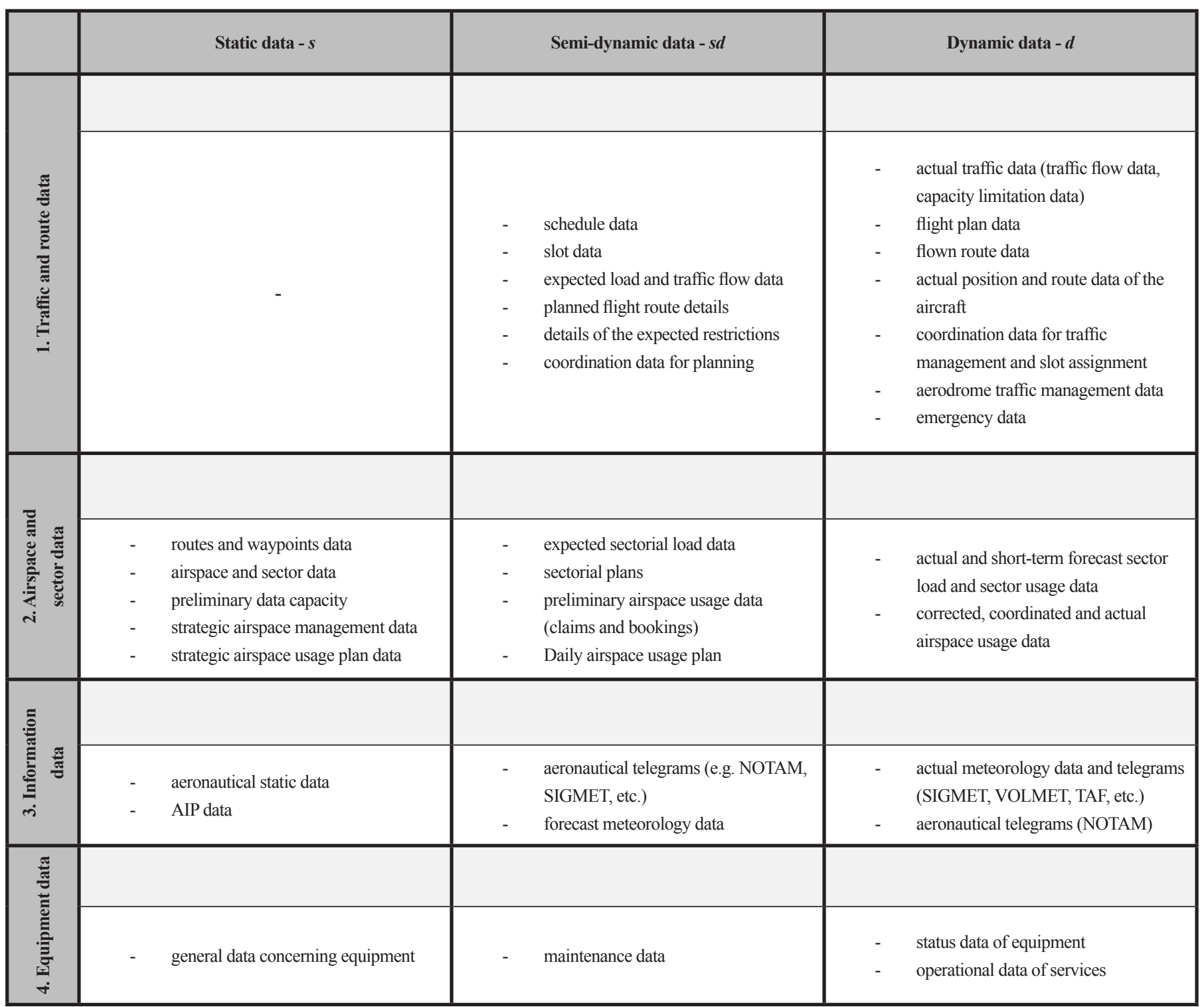


Table 4 Machine systems

\begin{tabular}{|c|c|c|c|}
\hline $\begin{array}{l}\text { Nota- } \\
\text { tion }\end{array}$ & $\begin{array}{l}\text { Name of the system } \\
\text { group }\end{array}$ & $\begin{array}{l}\text { Nota- } \\
\text { tion }\end{array}$ & Name of the system \\
\hline $\mathbf{M}_{\mathbf{I}}$ & $\begin{array}{l}\text { Airspace Management } \\
\text { System }\end{array}$ & $\mathbf{M}_{1}$ & $\begin{array}{l}\text { LARA - Local And sub-Regional Airspace Management Support System (system which provides centralized } \\
\text { capacity management and it ensures airspace usage data on a European scale across the borders, interoperable) }\end{array}$ \\
\hline \multirow{3}{*}{$\mathbf{M}_{\mathrm{II}}$} & \multirow{3}{*}{$\begin{array}{l}\text { Systems for air traffic } \\
\text { flow management }\end{array}$} & $\mathbf{M}_{2}$ & $\begin{array}{l}\text { IFPS - Integrated Initial Flight Plan Processing System } \\
\text { (central flight plan processing system operated by the EUROCONTROL) }\end{array}$ \\
\hline & & $\mathbf{M}_{3}$ & $\begin{array}{c}\text { ETFMS - Enhanced Tactical Flow Management System (flow management system which provides temporal } \\
\text { forecast about the expected traffic situations) }\end{array}$ \\
\hline & & $\mathbf{M}_{4}$ & CASA - Computer Assisted Slot Allocation (slot coordination system) \\
\hline \multirow[t]{2}{*}{$\mathbf{M}_{\mathrm{III}}$} & \multirow[t]{2}{*}{$\begin{array}{l}\text { Systems for air traffic } \\
\text { services }\end{array}$} & $\mathbf{M}_{5}$ & $\begin{array}{l}\text { Complex air traffic control system } \\
\text { (radar and flight data processing, information display for the operative users, supervision and management } \\
\text { function for the technical staff) e.g. MATIAS (Magyar AuTomated and Integrated Air Traffic Control System) by Thales }\end{array}$ \\
\hline & & $\mathbf{M}_{6}$ & Back - up air traffic control system (backup radar and flight data display system) \\
\hline \multirow{4}{*}{$\mathbf{M}_{\mathrm{IV}}$} & \multirow{4}{*}{$\begin{array}{l}\text { Communications } \\
\text { systems }\end{array}$} & $\mathbf{M}_{7}$ & $\begin{array}{l}\text { Voice communication system (Speech communication between the air traffic controllers (within and outside the } \\
\text { country) and external ATS services) }\end{array}$ \\
\hline & & $\mathbf{M}_{8}$ & $\begin{array}{l}\text { Radio and data communication system (Air-ground connection on 118-137 MHz (VHF) and 225-400 } \mathrm{MHz} \\
\text { (UHF) frequency and the ground-air datalink - CPDLC) }\end{array}$ \\
\hline & & $\mathbf{M}_{9}$ & $\begin{array}{c}\text { AFTN network - Aeronautical Fixed Telecommunication Network (network witch provide the management and } \\
\text { transmission of operative aviation data and aviation related announcements) }\end{array}$ \\
\hline & & $\mathbf{M}_{10}$ & $\begin{array}{l}\text { OLDI connections - on-line data interchange (ensure the exchange of operational flight data with the adjacent } \\
\qquad \text { ATC units through the aviation announcements) }\end{array}$ \\
\hline \multirow{3}{*}{$\mathbf{M}_{\mathbf{v}}$} & \multirow{3}{*}{ Navigation systems } & $\mathbf{M}_{11}$ & Ground based navigation devices (VOR, DME, NDB) \\
\hline & & $\mathbf{M}_{12}$ & Runway status signalling and ILS control system \\
\hline & & $\mathbf{M}_{13}$ & Aerodrome lighting system \\
\hline \multirow{2}{*}{$\mathbf{M}_{\mathrm{VI}}$} & \multirow{2}{*}{$\begin{array}{c}\text { Surveillance } \\
\text { systems }\end{array}$} & $\mathbf{M}_{14}$ & $\begin{array}{l}\text { A-SMGCS - Advanced Surface Movement Guidance and Control System } \\
\text { (monitoring and control system for the ground movement) }\end{array}$ \\
\hline & & $\mathbf{M}_{15}$ & $\begin{array}{l}\text { Terminal and en-route area surveillance radar equipment (surveillance equpiment for the monitor of the } \\
\text { airport vicinity and the en-route area - primary, secondary and MODE-S radar systems) }\end{array}$ \\
\hline \multirow[t]{2}{*}{$\mathbf{M}_{\mathrm{VII}}$} & \multirow{2}{*}{$\begin{array}{l}\text { Systems for } \\
\text { aeronautical } \\
\text { information services }\end{array}$} & $\mathbf{M}_{16}$ & $\begin{array}{l}\text { Automatic terminal information service (ATIS) (Radio system of the automatic terminal information } \\
\text { service, which insures actual, routine aviation and airport information for the arriving and departing aircrafts) }\end{array}$ \\
\hline & & $\mathbf{M}_{17}$ & EAD - European AIS Database (European database which contains all aviation related static data) \\
\hline \multirow[t]{2}{*}{$\mathbf{M}_{\mathrm{VIII}}$} & \multirow{2}{*}{$\begin{array}{l}\text { Systems for the use of } \\
\text { meteorological } \\
\text { information }\end{array}$} & $\mathbf{M}_{18}$ & $\begin{array}{l}\text { Aerodrome meteorology data collection and processing system } \\
\text { (ensure data collection and the preparation of the aviation meteorology telegrams) }\end{array}$ \\
\hline & & $\mathbf{M}_{19}$ & Aerodrome and aviation meteorological forecasting system \\
\hline
\end{tabular}

\subsection{Enhancement of the model resolution}

All components of the model of the system of information can be divided into lower-level elements. Figure 3 illustrates the enhancement of the resolution of the components. The inverted pyramid represents the decreasing elements as the resolution becomes more detailed. The extension and the numerosity of the elements are in inverse proportion. The expressions in the brackets contain the notation of the elements for all resolution levels at each component. The expressions clearly identify which element belongs to which component.

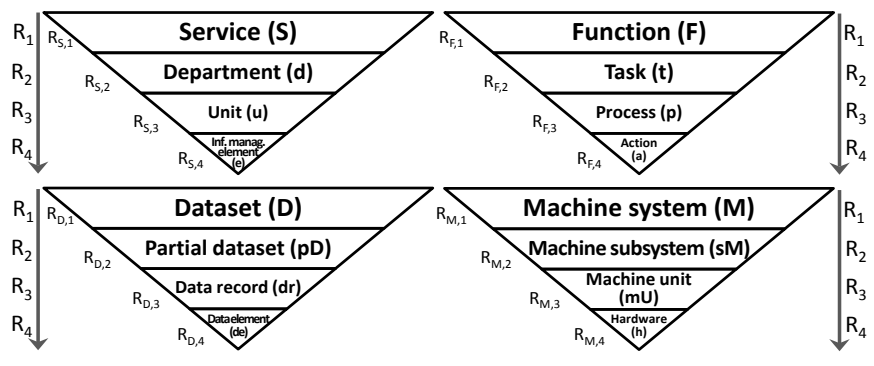

Fig. 3 The vertical enhancement of the model of the system of information by components) 


\subsection{Step 2: Analysis of the Functions (S-F connections)}

After the identification of the components, the services and functions were assigned. Based on the services and within them based on the duties, the functions to be fulfilled by the services were identified. In this way, the functions were assigned to the services. Table 5 illustrates the result. Due to the high standardization of the aviation industry the functions and services are clearly matched with minimal overlap. Overlaps exist only at the level of the functions, tasks and processes are free of overlaps.

\subsection{Step 3: Information assignment}

In view of the fulfilled tasks of the services, the managed information was identified and it appears in the data structural matrix. Table 6 illustrates the structure of the matrix. The row headers of the table show the services and the functions. The cells of the vertical columns contain the managed information related to the fulfilled function by the services sorted into datasets. The cells of the matrix contain the managed part datasets.

The knowledge of the function is not enough for the identification of the managed information because several tasks belong to a specific function. Thus the modelling needs deeper analysis on the level of service-function assignment. The functions have been divided into tasks. The tasks belonging to the fulfilment of the functions for each service have been identified. The service-function assignment was the basis of the determination of the managed datasets.

\section{The data structural model}

The data structural model is the structure of the managed information according to the components. The model summarizes what kind of datasets are required for the operation of a certain function in a given service. The model is a structured data structure for the identification and classification of the managed information related to air traffic control. The representation of the model is a matrix. The managed information sets are indicated in the cells (Fig. 4). Machine components may be indicated in the matrix connected to the managed information, in view of the information managing actions fulfilled by the machines.

This model describes the structure of the data, so it does not contain the stages and modes of the data procession. Latter is connected to the operations which are influenced by several factors e.g. applied computing algorithm, physical infrastructure, broad and scope of information sharing, etc.

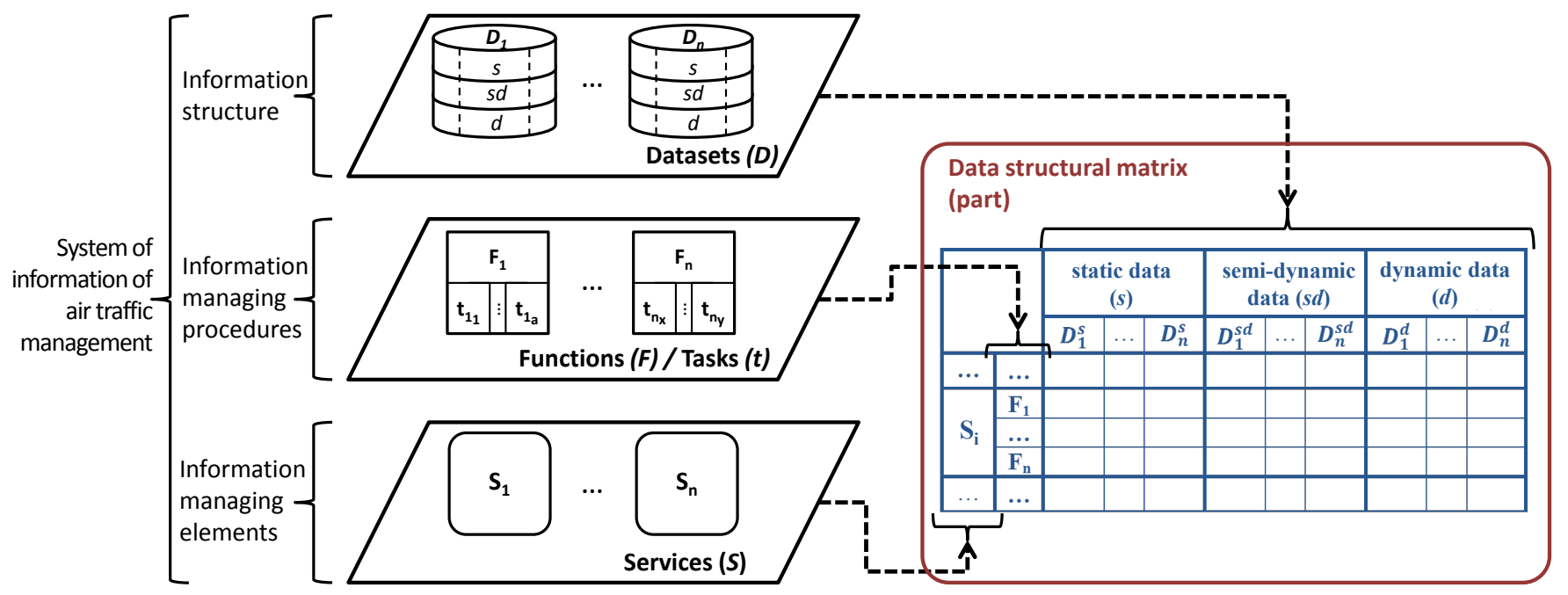

Fig. 4 System of information model of the air traffic management 
Table 5 Assignment of services and functions

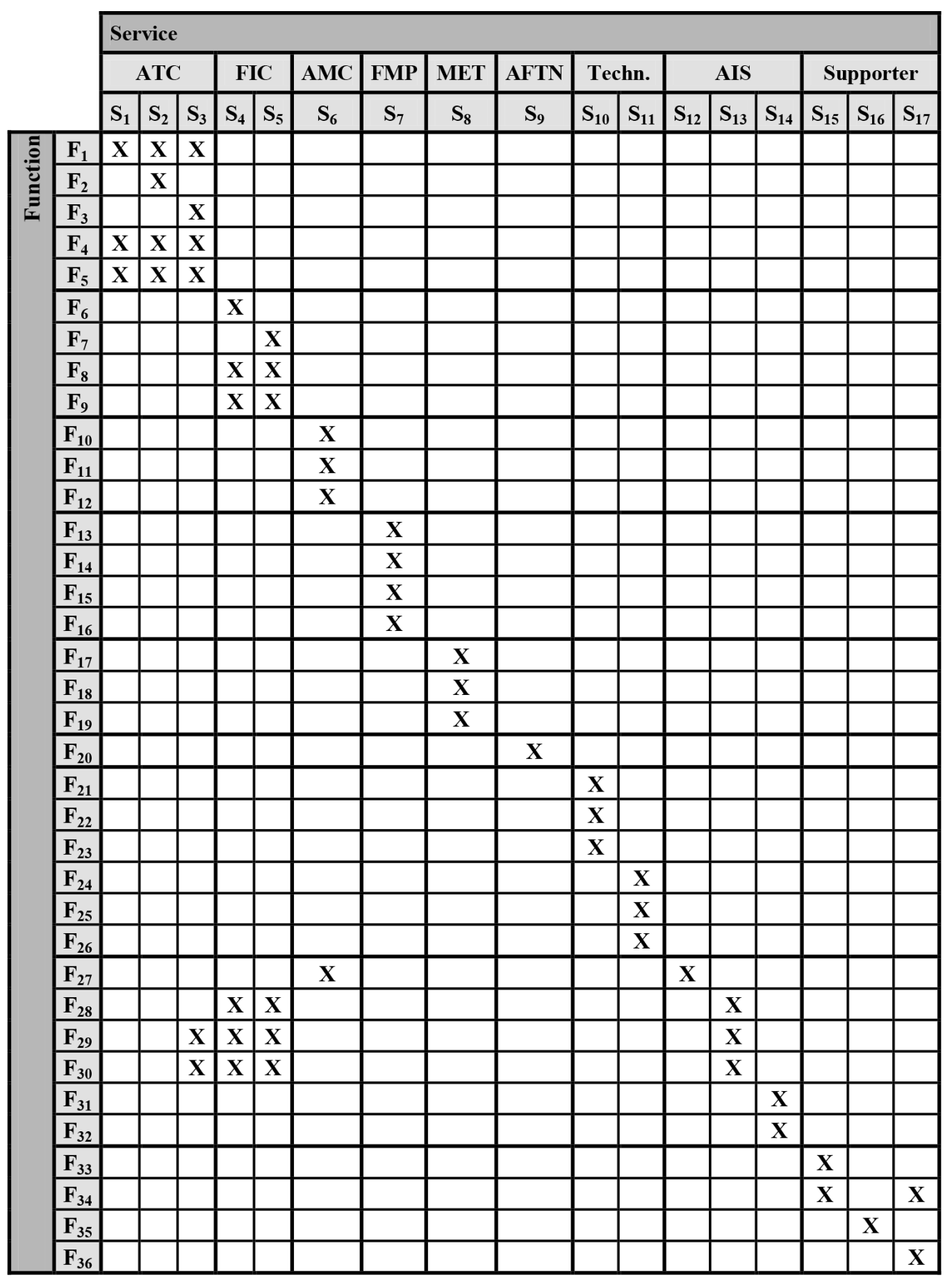

Table 6 Structure of the data structural matrix

\begin{tabular}{|c|c|c|c|c|c|c|c|c|c|}
\hline \multirow[b]{2}{*}{$\mathbf{S}_{\mathbf{i}}$} & \multirow[b]{2}{*}{$\mathbf{F}_{\mathbf{i}}$} & \multicolumn{3}{|c|}{ static data } & \multicolumn{3}{|c|}{ semi-dynamic data } & \multicolumn{2}{|c|}{ dynamic data } \\
\hline & & $D_{1}^{s}$ & $\cdots$ & $D_{4}^{s}$ & $D_{1}^{s d}$ & $\ldots$ & $D_{4}^{s d}$ & $D_{1}^{d}$ & $D_{4}^{d}$ \\
\hline \multirow{3}{*}{$\mathbf{S}_{1}$} & $\mathbf{F}_{\mathbf{1}}$ & & & & & & & & \\
\hline & $\ldots$ & & & & & & & & \\
\hline & $F_{39}$ & & & & & & & & \\
\hline \multirow{3}{*}{$\cdots$} & $\mathbf{F}_{1}$ & & & & & & & & \\
\hline & $\ldots$ & & & & & & & & \\
\hline & $F_{39}$ & & & & & & & & \\
\hline \multirow{3}{*}{$\mathbf{S}_{18}$} & $\mathbf{F}_{1}$ & & & & & & & & \\
\hline & $\ldots$ & & & & & & & & \\
\hline & $\mathbf{F}_{39}$ & & & & & & & & \\
\hline
\end{tabular}




\section{Summary - application potential and further outlook}

International industry members support the integrated management of air traffic data and the joint access. The elaborated model allows the integrated management of information, thus ensuring fast and cost efficient information transmission between the industry members. The integration requires significant time and consists of several steps. The elaborated system of information model contributes to the first part of the mentioned integration.

The availability of new technical solutions regarding to the capacities in the field of computing and storage allow real time procession and transmission of large amounts of data generated in the aviation industry. The fragmentation of the aviation systems and the dependency exposure to the data holders can mitigated by the realization of the integration. At the same time quick and accurate access to the data can be insured even if a single component falls out of the network.

With the spread of cloud-based services and the implementation of new security solutions the remote management of critical data becomes available, thus accessibility is improving. Along with this the spread of new industrial services is expected, for which the necessary integration platform is provided by systems allowing integrated data management and worldwide accessibility produced by the international lead data warehouses - similar to the operation of the airline IT systems. The complex and integrated services support the activities of the future air traffic control across the borders, with global extension, thus simplifying the operation of the services.

In the SESAR programme (Single European Sky ATM Research) intelligent solutions are going to be applied in the field of air transportation. These new initiatives are based on the full utilization of common and standardized data exchange between various systems in order to ensure a higher level of safety and fluidity of air transport worldwide. Some solutions and applications are available even now, which are driven by the continuous data exchange between remote stations (virtual towers, remotely controlled airspaces, etc.). Interoperability is the key for these kind of operations (Schváb and MarkovitsSomogyi, 2015).

In the future joint and synchronized development with common aims are necessary in order to explore the latent needs and the full exploitation of the available capacity. The higher level of data management contributes to the cost effective development of the air transport management sector.

In the near future the most difficult task is the design and later the implementation of the optimal comprehensive data management operations, which need to be solved in order to provide integrated and common services between the industry partners.

\section{Conclusions}

The main contributions:

- The organizational structure, the information management processes and the managed information of air traffic control have been revealed and identified with the use of system thinking approach.

- The systematic information management structure has been created for the comprehensive management of aviation and air traffic management related information.

- The elaborated model allows the integrated management of all information at each step of a flight.

- No similar approach has been presented previously in the field of the research.

\section{The key findings:}

- Previous scientific publications dealt with modelling, but the functional models applied to only a few actions connected to human factor analysis. No comprehensive functional analysis of the whole air traffic management system was mentioned.

- The common terminology for "functions", "modelling" and "structure" is missing in the publications, thus all researchers define them individually and differently and in most cases the exact definitions are also missing.

- The available modelling techniques elaborated for the comprehensive analysis of large-scale systems (e.g. FARM and IDEF0) can be used in aviation, in the field of the modelling of air traffic management systems, but their use have not been applied yet.

- The aviation industry requires integrated data and information management, but the comprehensive data management solutions are missing due to the intense fragmentation of the applied information systems and the industry.

\section{The lessons learnt:}

- System developers and system warehouses have a huge amount of information of the industrial needs in the field of air traffic control but they use them for their own purposes and do not publish them, while researchers need this kind of information for scientific reasons.

- Integration and interoperability are key questions even in aviation, where standardization has the highest level in transportation.

- The spread of new technologies like high speed, broadband, interoperable, available, standardized communication technologies with the use of shared and cloud based systems will pull the industry and they will be the solutions and the basis of the services in the future. 


\section{References}

Ahmad, S, Saxena, V. (2008). Design of Formal Air Traffic Control Systemt Through UML. Ubiquitous Computing and Communication Journal. 3(6), pp. 11-20.

Bayen, A. (2003). Computational control of networks of dynamical systems: application to the National Airspace System. PhD Thesis, Department of Aeronautics and Astronautics, Stanford University.

Bayen, A., Tomlin, C. (2005). A case study: Air Traffic Management systems. In: EOLSS - Control Systems, Robotics and Automation, EOLSS Publishers Co. Ltd. Ref: 6:43:28:8

Boeing Commercial Airplane Group. Air Traffic Management Concept Baseline Definition, NEXTOR Report \# RR-97-3, Oct. 31, 1997.

EUROCONTROL - SESAR: SWIM Concept of Operations. 2013.

European Organisation for the Safety of Air Navigation - Model of the Cognitive Aspects of Air Traffic Control. HUM.ET1.ST01.1000-REP-02 1997.

Filho, D. A., Falcão, E. A. (2012). Analysis of Airspace Traffic Structure and Air Traffic Control Techniques. Department of Aeronautics and Astronautics, Massachusetts Institute of Technology. URL: http://dspace.mit. edu/handle/1721.1/7582

Haraldsdottir, A., Schwab, R. W., Alcabin, M. S. (1998). Air Traffic Management Capacity-Driven Operational Concept Through 2015. In: 2nd USA/ EUROPE AIR TRAFFIC MANAGEMENT R\&D SEMINAR Orlando, Dec. 1-4, 1998.

Hollnagel, E. (2004). Barriers and accident prevention. Aldershot, Ashgate, $\mathrm{UK}, 226 \mathrm{p}$.

ICAO Doc 10039 - MANUAL ON SYSTEM WIDE INFORMATION MANAGEMENT (SWIM) CONCEPT. International Civil Aviation Organization. 999 Robert Bourassa Boulevard, Montréal, Quebec, Canada H3C 5H7

Kampichler, W., Eier, D. (2014). A D-MILS console subsystem for advanced ATM communication services. In: Digital Avionics Systems Conference (DASC), 2014 IEEE/AIAA 33rd. 5-9 Oct. 2014 Colorado Springs, CO pp. 6D2-1 - 6D2-8. https://doi.org/10.1109/DASC.2014.6979505
Loft, S., Sanderson, P., Neal, A., Mooij, M. (2007). Modeling and predicting mental workload in en route air traffic control: Critical review and broader implications. Human Factors The Journal of the Human Factors and Ergonomics Society. 49(3), pp. 376-399. https://doi.org/10.1518/001872007X197017

Marca, D. A., McGowan, C. L. (1988). SADT: Structured analysis and design technique. McGraw-Hill.

Schváb Z., Markovits-Somogyi R. (2015) Reopening the Kosovo Upper Airspace - Analyzing the First Year of Operations. 4th International Conference on Models and Technologies for Intelligent Transportation Systems (MT-ITS). $536 \mathrm{p}$.

Menon P. K., Sweriduk, G. D., Bilimoria, K. D. (2004). New Approach for Modeling, Analysis, and Control of Air Traffic Flow. Journal of Guidance, Control, and Dynamics. 27(5), pp. 737-744. https://doi.org/10.2514/1.2556

Nolan, M. (2010). Fundamentals of Air Traffic Control. Cengage Learning Prandini, M., Piroddi, L., Puechmorel, S., Brazdilova, S. L. (2011). Toward air traffic complexity assessment in new generation air traffic management systems. IEEE Transactions on Intelligent Transportation Systems. 12(3), pp. 809-818. 2011. https://doi.org/10.1109/TITS.2011.2113175

Reports on Leading Edge Engineering from the 1997 NAE Symposium on Frontiers of Engineering. National Academy of Engineering. National Academies Press, (1998).

Ross, D. T. (1977). Structured Analysis (SA): A language for communicating ideas. IEEE Transactions on Software Engineering. SE-3(1), pp. 16-34. https://doi.org/10.1109/TSE.1977.229900

Ross, D. T. (1985). Applications and extensions of SADT. Computer. 18(4), pp. 25-34. https://doi.org/10.1109/MC.1985.1662862

Woltjer, R., Hollnagel, E. (2008). Functional modeling for risk assessment of automation in a changing air traffic management environment. In: 4th International Conference on Working on Safety.

Zellweger, A. G., Donohue, G. L. (2001). Air Transportation Systems Engineering. American Institute of Aeronautics and Astronautics. https://doi.org/10.2514/4.866630 